\title{
Smartphone Addiction and Its Impact on Knowledge, Cognitive, and Psychomotor Skills of the Dental Students at Jazan University
}

\author{
Syed Nahid Basheer ${ }^{1}$, Tahani Mohammed Arishi ${ }^{2}$, Nasreen Albar ${ }^{3}$, Syed Wali Peeran ${ }^{4}$, Syed Ali Peeran ${ }^{5}$, Mohammed Zameer $^{6}$
}

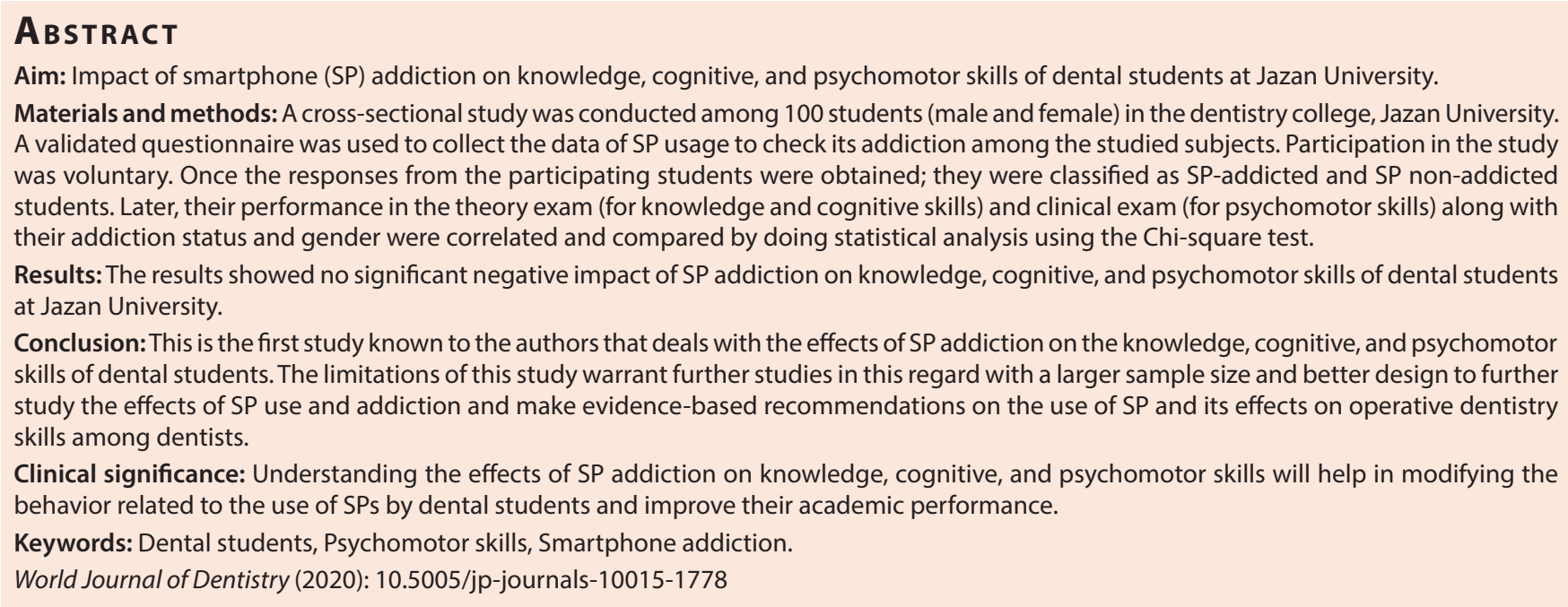

\section{INTRODUCTION}

The internet with the introduction of smart mobile gadgets has become an integral part of human-human communication. Smartphones (SPs) are powerful and useful tools as they offer combined services of the mobile phone and the internet. They have different purposes which include entertainment, electronic commerce, cultural exchange, rapid information transfer, and dissemination. In medicine and dentistry, it is used for the dissemination of public health information, telemedicine, and virtual learning for dental and medical students. ${ }^{1-8}$ Moreover, SPs offer the benefits of social media-multifunctional networking tools usage at the convenience of our palms; content production (blogs [Blogger, Tumblr], information aggregation (Wikipedia), media sharing (YouTube, Tik Tok, Flickr, Instagram Wikimedia commons), microblogs/Tumblelogs [Twitter, Sina weibo]), social networking (Twitter, Facebook, MySpace, Google Plus), professional networking (LinkedIn), virtual reality, and gaming environments (Second Life) are all widely used. ${ }^{9,10}$ The constant use of these social networking spaces have changed the way we socially interact. It has become the prime medium of expression and communication rendering life without their use unthinkable. ${ }^{5}$

Studies have shown that overuse of SPs can cause behavioral problems including impulse control disorders, lessen social interaction, attenuate physical activity, can cause relationship problems, harm academic and professional performance, and could lead to physical ailments like blurred vision, problems in the eardrum, and musculoskeletal pain in wrists and back of the neck. They could also cause fatigue and sleep disorders. Thus, 1,30partment of Restorative Dental Sciences, College of Dentistry, Jazan University, Jazan, Kingdom of Saudi Arabia

${ }^{2}$ Al-Deraiya Primary Care Clinic, Jazan, Saudi Arabia

${ }^{4}$ Department of Periodontics, Armed Forces Hospital, Jazan, Kingdom of Saudi Arabia

${ }^{5}$ Department of Prosthodontics Armed Forces Hospital, Jazan, Kingdom of Saudi Arabia

${ }^{6}$ Department of Pedodontics Armed Forces Hospital, Jazan, Kingdom of Saudi Arabia

Corresponding Author: Syed Nahid Basheer, Department of Restorative Dental Sciences, College of Dentistry, Jazan University, Jazan, Kingdom of Saudi Arabia, Phone: +966538476220 , e-mail: drsyedmds@gmail.com

How to cite this article: Basheer SN, Arishi TM, Albar N, et al. Smartphone Addiction and Its Impact on Knowledge, Cognitive, and Psychomotor Skills of the Dental Students at Jazan University. World J Dent 2020;11(6):468-473.

Source of support: Nil

Conflict of interest: None

excessive SPs use can hamper both physical and mental health..$^{5,11-15}$ Smartphone addiction is considered as the inability to limit the usage of SPs despite adverse effects on users. Several questionnairebased scales are in use to measure the self-described addiction, problematic behavior due to SP use, nomophobia, and internet addiction. ${ }^{11,16-18}$ Smartphone addiction proneness scale (SAPS) questionnaire by Kim et al. has been used in this study which was 
developed based on the previous existing questionnaires on the internet and phone addiction, it is validated and appears to be reliable for screening adolescents for SP addiction. ${ }^{19}$

There is a building view in the medical community that the use of a two-dimensional flat screen and excessive internet usage results in loss of creativity and manual dexterity, which could hamper clinical skills among students. ${ }^{20-22}$ However, others have a view that various uses of the internet could improve manual dexterity; gaming could improve concentration and dexterity while texting could help reflexes get faster. ${ }^{23}$ Hence, this study was designed to study SP usage, its addiction among final year dental students at Jazan University, and its possible effects on knowledge, cognitive, and psychomotor skills (manual dexterity) in clinical operative dentistry.

\section{Materials and Methods}

This is a cross-sectional study done among the fifth-year dental students aged between 20 years and 25 years who were attending clinical operative dentistry course. This study was designed to check the effect of SPs use and addiction on their academic performance and manual clinical dexterity of the students. Participation in this study was voluntary and a random sampling method was adopted. This study was conducted over a period of 2 months, from March to April 2019. The 100 subjects who accepted participation by signing the informed consent were included in this study. The electronic questionnaires were distributed to the students who appeared for both the theory and clinical final exams. Those who missed either of the exams (theory/clinical) were excluded from the study. All the students who attended the exams (53 males and 47 females) participated in the study. All the participants completed the questionnaire within a day. Any ambiguity was clarified and the completeness of the forms was checked.

The ethical committee of the Institutional Review Board of the College of Dentistry, Jazan University, Kingdom of Saudi Arabia, approved the study.

\section{Questionnaire Details}

A validated SAPS was used to measure the prevalence of SP addiction $^{19}$ (Table 1).

This scale consists of 15 self-rating questions, which were subdivided into three subdomains, including disturbance of adaptive functions, virtual life orientation, withdrawal and tolerance.

These questions were rated on a 4-point Likert-type scale from 1 (strongly disagree) to 4 (strongly agree).

Between the score range of 15 and 60, 42 was selected as a clinical cutoff score to consider a student was addicted and some questions to avoid response bias were scored in reverse order as recommended by the article. ${ }^{19}$

\section{Knowledge, Cognitive, and Psychomotor Skills Evaluation}

The theory exam in operative dentistry included a series of examinations with question papers consisting of short answers, short essays, and multiple-choice questions to evaluate the knowledge and cognitive skills of the students whereas the psychomotor skills were assessed by conducting a clinical exam which included assessment of preoperative procedures, cavity preparation, restorative procedures, and time management. Two qualified clinical examiners assessed the subjects and agreed upon marks were assigned to the students based upon predetermined rubrics approved by the department.

The exam results were converted to grades from I to $\mathrm{VI}$, the distribution of grades percentage was as follows, I (90-100\%), II (80-89\%), III (70-79\%), IV (60-69\%), and VI (59\% and less).

\section{Statistical Analysis}

Data collected were entered in MS Excel and tabulated accordingly by one of the independent investigators. The statistical analysis was done using SPSS ver 23. (IBM, USA) by an independent biostatistician, a significance value (a) $p<0.05$ was considered to be statistically significant, and the confidence interval was

Table 1: Smartphone addiction proneness scale ${ }^{19}$

\begin{tabular}{|c|c|c|c|c|c|}
\hline No. & Contents & Strongly disagree & Disagree & Agree & Strongly agree \\
\hline 1 & My school grades dropped due to excessive smartphone use. & 1 & 2 & 3 & 4 \\
\hline 2 & $\begin{array}{l}\text { Using a smartphone is more enjoyable than spending time with family } \\
\text { or friends. }\end{array}$ & 1 & 2 & 3 & 3 \\
\hline 3 & I cannot imagine my life without a smartphone. & 1 & 2 & 3 & 3 \\
\hline 4 & I tried to reduce the time I spend on a smartphone but failed. & 1 & 2 & 3 & 3 \\
\hline 5 & $\begin{array}{l}\text { I have a hard time doing what I have planned (study, do homework, or } \\
\text { go to after-school classes) due to using a smartphone. }\end{array}$ & 1 & 2 & 3 & 3 \\
\hline 6 & When I cannot use a smartphone, I feel like I have lost the entire world. & 1 & 2 & 3 & 3 \\
\hline 7 & I get anxious and nervous without a smartphone. & 1 & 2 & 3 & 3 \\
\hline $8^{*}$ & I can control my smartphone usage time. & 1 & 2 & 3 & 3 \\
\hline 9 & People frequently comment on my excessive smartphone use. & 1 & 2 & 3 & 3 \\
\hline $10^{*}$ & I am not anxious without a smartphone. & 1 & 2 & 3 & 3 \\
\hline 11 & Even when I know I should stop, I continue to use my smartphone. & 1 & 2 & 3 & 3 \\
\hline 12 & Family or friends complain that I use my smartphone too much. & 1 & 2 & 3 & 3 \\
\hline $13^{*}$ & My smartphone does not distract me from studying. & 1 & 2 & 3 & 3 \\
\hline 14 & I panic when I cannot use my smartphone. & 1 & 2 & 3 & 3 \\
\hline 15 & Spending a lot of time on a smartphone has become my habit. & 1 & 2 & 3 & 3 \\
\hline
\end{tabular}

${ }^{*}$ Questions scored in reverse order to avoid a response bias 
set at $95 \%$ with a power of the test $(\beta)$ of $80 \%$. Frequencies and percentages were used for categorical variables in descriptive analysis. Continuous variables were presented as mean with standard deviation. Pearson's Chi-square test was used for testing any statistically significant association of categorical variables.

\section{Results}

In this cross-sectional study 100 students participated, among them, 53 were male students and 47 were female students. This study showed that 3.8\% $(N=2)$ male students and $4.3 \%(N=2)$ female students studied were addicted to SP usage. Although female students were relatively more addicted to SP usage; however, it was not statistically significant (Table 2).

The exams for students were conducted as a theory exam (exam A) and clinical exam (exam B) in operative dentistry. Among addicted students in exam $A, 25 \%(N=1)$ got grade III and $75 \%$ $(N=3)$ students got $\mathrm{D}$ (Table 3 ). In exam $\mathrm{B}$, all the addicted students $[N=4(100 \%)]$ got grade III (Table 4). However, these results showed no statistical significance when the addicted and non-addicted subjects were compared. The cumulative grades (exam A + exam B) among addicted students showed that $25 \%(N=1)$ got grade III while $75 \%(N=3)$ students got grade IV. The cumulative results showed that $75 \%$ of addicted students got the lowest grades (Table 5). Nevertheless, the results were not statistically significant. In exam $A$, the male students' (mean $=68.7 \%$ ) performance was relatively better than female students (mean $=67.825)$ whereas, in exam B, the male students' (mean was $79.96 \%$ ) performance was relatively poorer than the female students (81.43). In the case of a combined exam $(A+B)$ results, female students (73.64\%) performed relatively better than male students (73.52\%). However, these results were not statistically significant (Table 6).

Table 2: Mobile phone addiction

\begin{tabular}{llccc}
\hline Gender of students & & Frequency & Percent & Pearson Chi-square test \\
\hline Male & Addicted & 2 & 3.8 & 0.015 \\
& Not addicted & 51 & 96.2 & \\
Female & Total & 53 & 100.0 & \\
& Addicted & 2 & 4.3 & \\
& Not addicted & 45 & 95.7 & \\
Total & Total & 47 & 100.0 & \\
& Addicted & 4 & 4 & \\
\hline
\end{tabular}

${ }^{*} p$ value $<0.05$ is considered statistically significant

NS: not significant

Table 3: Exam A grades and mobile phone addiction

\begin{tabular}{|c|c|c|c|c|c|c|c|c|c|}
\hline & & \multicolumn{5}{|c|}{ Exam $A$ grades } & \multirow[b]{2}{*}{ Total } & \multirow{2}{*}{$\begin{array}{l}\text { Pearson Chi- } \\
\text { square test }\end{array}$} & \multirow[b]{2}{*}{$p$ value* } \\
\hline & & Grade I & Grade II & Grade III & Grade IV & Grade VI & & & \\
\hline \multirow[t]{2}{*}{ Addicted } & $N$ & 0 & 0 & 1 & 3 & 0 & 4 & 6.250 & 0.181 (NS) \\
\hline & $\%$ & 0.0 & 0.0 & 25.0 & 75.0 & 0.0 & 100.0 & & \\
\hline \multirow{2}{*}{$\begin{array}{l}\text { Not ad- } \\
\text { dicted }\end{array}$} & $N$ & 1 & 13 & 39 & 21 & 22 & 96 & & \\
\hline & $\%$ & 1.0 & 13.5 & 40.6 & 21.9 & 22.9 & 100.0 & & \\
\hline \multirow[t]{2}{*}{ Total } & $N$ & 1 & 13 & 40 & 24 & 22 & 100 & & \\
\hline & $\%$ & 1.0 & 13.0 & 40.0 & 24.0 & 22.0 & 100.0 & & \\
\hline
\end{tabular}

${ }^{*} p$ value $<0.05$ is considered statistically significant

NS: not significant

Table 4: Exam B grades and mobile phone addiction

\begin{tabular}{|c|c|c|c|c|c|c|c|c|c|}
\hline & & \multicolumn{5}{|c|}{ Exam B grades } & \multirow[b]{2}{*}{ Total } & \multirow{2}{*}{$\begin{array}{l}\text { Pearson Chi- } \\
\text { square test }\end{array}$} & \multirow[b]{2}{*}{ pvalue* } \\
\hline & & Grade I & Grade II & Grade III & Grade IV & Grade VI & & & \\
\hline \multirow[t]{2}{*}{ Addicted } & $N$ & 0 & 0 & 4 & 0 & 0 & 4 & 7.095 & 0.069 (NS) \\
\hline & $\%$ & 0.0 & 0.0 & 100.0 & 0.0 & 0.0 & 100.0 & & \\
\hline \multirow{2}{*}{$\begin{array}{l}\text { Not ad- } \\
\text { dicted }\end{array}$} & $N$ & 15 & 41 & 33 & 7 & 0 & 96 & & \\
\hline & $\%$ & 15.6 & 42.7 & 34.4 & 7.3 & 0 & 100.0 & & \\
\hline \multirow[t]{2}{*}{ Total } & $N$ & 15 & 41 & 37 & 7 & 0 & 100 & & \\
\hline & $\%$ & 15.0 & 41.0 & 37.0 & 7.0 & 0.0 & 100.0 & & \\
\hline
\end{tabular}

${ }^{*} p$ value $<0.05$ is considered statistically significant NS: not significant 
Impact of Smartphone Addiction on Dental Students

Table 5: Total grades and mobile phone addiction

\begin{tabular}{|c|c|c|c|c|c|c|c|c|c|}
\hline & & \multicolumn{5}{|c|}{ Exam $A+$ Exam $B$} & \multirow[b]{2}{*}{ Total } & \multirow{2}{*}{$\begin{array}{l}\text { Pearson Chi- } \\
\text { square test }\end{array}$} & \multirow[b]{2}{*}{$p$ value ${ }^{*}$} \\
\hline & & Grade I & Grade II & Grade III & Grade IV & Grade VI & & & \\
\hline \multirow[t]{2}{*}{ Addicted } & $N$ & 0 & 0 & 1 & 3 & 0 & 4 & 3.680 & 0.451 (NS) \\
\hline & $\%$ & 0.0 & 0.0 & 25.0 & 75.0 & 0.0 & 100.0 & & \\
\hline \multirow{2}{*}{$\begin{array}{l}\text { Not ad- } \\
\text { dicted }\end{array}$} & $N$ & 3 & 26 & 34 & 30 & 3 & 96 & & \\
\hline & $\%$ & 3.1 & 27.1 & 35.4 & 31.3 & 3.1 & 100.0 & & \\
\hline \multirow[t]{2}{*}{ Total } & $N$ & 3 & 26 & 35 & 33 & 3 & 100 & & \\
\hline & $\%$ & 3.0 & 26.0 & 35.0 & 33.0 & 3.0 & 100.0 & & \\
\hline
\end{tabular}

${ }^{*} p$ value $<0.05$ is considered statistically significant

NS: not significant

Table 6: Comparison of mean marks of students according to gender

\begin{tabular}{|c|c|c|c|c|c|c|c|}
\hline & $\begin{array}{l}\text { Gender of } \\
\text { students }\end{array}$ & $N$ & Mean & Percentage & Std. deviation & Students " $t$ " test & pvalue ${ }^{*}$ \\
\hline \multirow[t]{2}{*}{ Exam A (total 40) } & Male & 53 & 27.48 & 68.7 & 4.24 & 0.38 & 0.705 (NS) \\
\hline & Female & 47 & 27.13 & 67.825 & 5.06 & & \\
\hline \multirow[t]{2}{*}{ Exam B (total 30) } & Male & 53 & 23.99 & 79.9666667 & 2.27 & -1.001 & 0.319 (NS) \\
\hline & Female & 47 & 24.43 & 81.4333333 & 2.05 & & \\
\hline \multirow[t]{2}{*}{ Total exam (70) } & Male & 53 & 51.47 & 73.5285714 & 5.63 & -0.068 & 0.946 (NS) \\
\hline & Female & 47 & 51.55 & 73.6428571 & 6.33 & & \\
\hline
\end{tabular}

${ }^{*} p$ value $<0.05$ is considered statistically significant

NS: not significant

The results showed that $45 \%$ of students agree that due to excessive SP use their school grades dropped, while $55 \%$ of them disagree that SP usage is more enjoyable than spending time with family or friends.

Fifty-three percent of students disagreed that they cannot visualize their existence without an SP.

Fifty-two percent of students agreed that they tried reducing the time spent on an SP but failed in doing so.

Forty percent of students agreed that they had a hard time doing homework, study, and attend after-school classes due to using an SP.

Forty-one percent of students disagreed that when they are not using an SP, they feel like that they have lost the entire world, $48 \%$ disagreed that they get anxious and nervous without their SPs, $55 \%$ of students agreed that they can control their SP usage time, 52\% students disagreed that people frequently comment on their excessive SP use, $61 \%$ students agreed that they are not anxious without an SP.

Fifty-one percent of students agreed that even when they know they should stop, they continue to use their SP, 51\% of students disagreed that family and friends complain that they use SP too much, $51 \%$ of students disagreed that SP does not distract them from studying, $55 \%$ of students disagreed that they panic when they cannot use their SPs, 59\% of students agreed that spending a lot of time on their SPs has become their habit (Table 7).

\section{Discussion}

Smartphone use has become an integral part of the day-to-day life activities of students, including communication in professional life, family and friends, shopping, and its use for academic purposes like attending lectures, webinars, meetings especially in pandemic situations like COVID-19. Furthermore, nowadays, because of a shift from conventional hard copy books to ebooks, there is a tendency in students to read through ebooks because of convenience, it seems like the use of SP will be increasing in the coming days. Hence, it is very important to know the kind of impact SP usage has on the academic performance of students, including knowledge, cognitive, and psychomotor skills so that necessary guidelines and recommendations can be made accordingly.

Many studies have assessed the effect of SP usage on various aspects of the academic performance of university students. ${ }^{5,12}$ Scientific literature has emphasized, argued, and addressed the importance of studying the effect of SP on educators and dental students. ${ }^{5,6}$ Still, there were no studies found which have studied the impact of SP use on psychomotor skills of the students, specifically operative dentistry related psychomotor skills, which are one of the most basic skills required to be acquired by dental students to become competent dentists. This is the first study to the best of our knowledge to study the impact of SP usage and addiction on the manual dexterity of dentists in the field of operative dentistry.

Final year BDS students were chosen in the study because they have already obtained enough clinical training in operative dentistry and their clinical operative exam will be the last exam in the division of operative dentistry; it is expected that the students should be competent enough to perform all operative dentistry procedures for undergraduate students.

A validated SAPS was used to measure the prevalence of SP addiction ${ }^{19}$ (Table 1). This scale was used because it included questions on various aspects of the effects of SP use, including 
Table 7: Descriptive analysis of individual items in SP addiction proneness scale

\begin{tabular}{lcllc}
\hline Questions & $\begin{array}{l}\text { Strongly } \\
\text { disagree }(n)\end{array}$ & Disagree $(n)$ & Agree $(n)$ & $\begin{array}{c}\text { Strongly } \\
\text { agree }(n)\end{array}$ \\
\hline Q 1 & 9 & 38 & 45 & 8 \\
Q 2 & 24 & 55 & 20 & 1 \\
Q 3 & 4 & 8 & 53 & 35 \\
Q 4 & 5 & 30 & 52 & 13 \\
Q 5 & 7 & 39 & 40 & 14 \\
Q 6 & 13 & 41 & 34 & 12 \\
Q 7 & 14 & 48 & 34 & 4 \\
Q 8 & 2 & 31 & 55 & 12 \\
Q 9 & 18 & 52 & 22 & 8 \\
Q 10 & 5 & 25 & 61 & 9 \\
Q 11 & 7 & 30 & 51 & 12 \\
Q 12 & 11 & 51 & 32 & 6 \\
Q 13 & 3 & 51 & 39 & 7 \\
Q 14 & 12 & 55 & 27 & 6 \\
Q 15 & 3 & 25 & 59 & 13 \\
\hline
\end{tabular}

virtual life orientation, adaptive functions, withdrawal and tolerance. Also, the questions were rated on a 4-point Likert-type scale from 1 (strongly disagree) to 4 (strongly agree). To avoid response bias, some items were scored in reverse order. The clinical cutoff score was kept as 42.

For convenience, the questionnaire was prepared on google form, shared and the data were collected. The data were then transferred to MS Excel and the statistical analysis was carried over. The students were categorized into those who were addicted and those who were non-addicted to the SP use. The exam results of both the theory and clinical were used both individually and as cumulative ones and were compared with the addiction results of the subjects studied.

In the current study, it was found that $4.05 \%$ of students were considered addicted to SP use. Among the addicted students in the theory exam (exam A), $25 \%$ of students got grade III and $75 \%$ of students got grade IV. However, the results were not statistically significant. The results were in contrast to the studies published by Samaha and Hawi, ${ }^{12}$ Halboub et al., ${ }^{5}$ and Prasad et al. $^{24}$ showed the academic performance of the SP addicted students to have been adversely affected. This difference may be due to the difference in the psychometric scales employed and the size of the sample used.

It was also found from the study that male students' performance was relatively better in the theory exam than female students, whereas in the clinical exam, female students' performance was better than male students. Although in combined results female students performed better than male students which are reflected in an earlier study also. ${ }^{5}$ However, the results were not significant.

\section{Conclusion}

Within the limitations of this study, no statistically significant adverse effect was found on the use of SP on the academic and clinical operative skills of the dental students. However, this warrants further studies in this regard with larger sample sizes and better design to further study the effects of SP use and addiction and make evidence-based recommendations on the use of SP and its effects on operative dentistry skills among dentists.

\section{References}

1. Cha S-S, Seo B-K.Smartphone use and smartphone addiction in middle school students in Korea: prevalence, social networking service, and game use. Health Psychol Open 2018;5(1):205510291875504 $10.1177 / 2055102918755046$.

2. Lu T, Neng W. Future internet: the internet of things. IEEE 2010. V5-376-V5-380.

3. Internet economics McKnight LW, Bailey JP, ed., Cambridge, MA: MIT Press; 1997. p. 525. \$35.00; Computers \& mathematics with applications (1987). 1997;34(10):137.

4. Shabot MM. Medicine on the internet. Proceedings Baylor University Medical Center 2001;14(1):27-31. DOI: 10.1080/08998280.2001.11927727.

5. Halboub E, Othathi F, Mutawwam F, et al. Effect of social networking on academic achievement of dental students, Jazan University, Saudi Arabia. East Mediterr Health J 2016;22(12):865-871. DOI: 10.26719/2016.22.12.865.

6. Kömerik N. Health-care education: from lecture room to cyberspace. Dentist Med Res 2014;2(1):1-2. DOI: 10.4103/2348-1471.131555.

7. Komerik N. Use of the internet among dental students in Turkey. J Dent Educ 2005;69(4):470-475. DOI: 10.1002/j.00220337.2005.69.4.tb03935.x.

8. Khatoon $B$, Hill K, Walmsley AD. Mobile learning in dentistry: challenges and opportunities. Br Dent J 2019;227(4):298-304. DOI: 10.1038/s41415-019-0615-x.

9. Kietzmann JH, Hermkens K, McCarthy IP, et al. Social media? get serious! understanding the functional building blocks of social media. Bus Horiz 2011;54(3):241-251. DOI: 10.1016/j.bushor.2011.01.005.

10. Ventola CL. Social media and health care professionals: benefits, risks, and best practices. P\&T (Lawrenceville, NJ) 2014;39(7):491-520.

11. Kwon M, Lee J-Y, Won W-Y, et al. Development and validation of a smartphone addiction scale (SAS). PLoS ONE 2013;8(2):e56936. DOI: 10.1371/journal.pone.0056936.

12. Samaha M, Hawi NS. Relationships among smartphone addiction, stress, academic performance, and satisfaction with life. Comput Human Behav 2016;57:321-325. DOI: 10.1016/j.chb.2015.12.045.

13. Lemola S, Perkinson-Gloor N, Brand S, et al. Adolescents' electronic media use at night, sleep disturbance, and depressive symptoms in the smartphone age. J Youth Adolesc 2014;44(2):405-418. DOI: 10.1007/s10964-014-0176-x.

14. Hysing M, Pallesen S, Stormark KM, et al. Sleep and use of electronic devices in adolescence: results from a large population-based study. BMJ Open 2015;5(1):e006748. DOI: 10.1136/bmjopen-2014-006748.

15. Khan M. Adverse effects of excessive mobile phone use. Int J Occup Med Environ Health 2008;21(4):289-293. DOI: 10.2478/v10001-0080028-6.

16. Perry SD, Lee KC. Mobile phone text messaging overuse among developing world university students. Communicatio 2007;33(2):6379. DOI: 10.1080/02500160701685417.

17. King ALS, Valença AM, Silva AC, et al. "Nomophobia": impact of cell phone use interfering with symptoms and emotions of individuals with panic disorder compared with a control group. Clin Pract Epidemiol Ment Health 2014;10(1):28-35. DOI: 10.2174/1745017901410010028.

18. Lin Y-H, Chang L-R, Lee Y-H, et al. Development and validation of the smartphone addiction inventory (SPAI). PLoS ONE 2014;9(6):e98312. DOI: $10.1371 /$ journal.pone.0098312.

19. Kim D, Lee Y, Lee J, et al. Development of korean smartphone addiction proneness scale for youth. PLoS ONE 2014;9(5):e97920. DOI: 10.1371/journal.pone.0097920.

20. S Y. students "can"t sew or cut' because they spend too much time on screens, professor warns 2018 [Available from: https:// www.independent.co.uk/life-style/surgery-students-dexterity- 
smartphones-keyboards-screens-craft-skills-stitch-rogerkneebone-a8608201.html.

21. S C. Surgery students "losing dexterity to sew" ONLINE: BBC; 2018 [Available from: https://www.bbc.com/news/education-46019429.

22. M W. Raised on screens lack skills for surgery Online: theguardian. com; 2018 [online:[raised on screens lack skills for surgery]. Available from: https://www.theguardian.com/society/2018/oct/30/medicalstudents-raised-on-screens-lack-skills-for-surgery\#: :text=New\%20 medical\%20students $\% 20$ have $\% 20$ spent,a $\% 20$ leading $\% 20$
surgeon\%20has\%20warned.\&text=Kneebone\%20said\%20there\%20 had\%20been,smartphones\%20had\%20become\%20so\%20popular.

23. News $B$, Video games made me a better surgeon online: BBC News; 2018 [online:[Available from: https://www.bbc.com/news/ uk-46036095.

24. Prasad $M$, Patthi $B$, Singla $A$, et al. Nomophobia: a cross-sectional study to assess mobile phone usage among dental students. J Clin Diagnos Res 2017;11(2):ZC34-ZC39. DOI: 10.7860/JCDR/2017/ 20858.9341. 